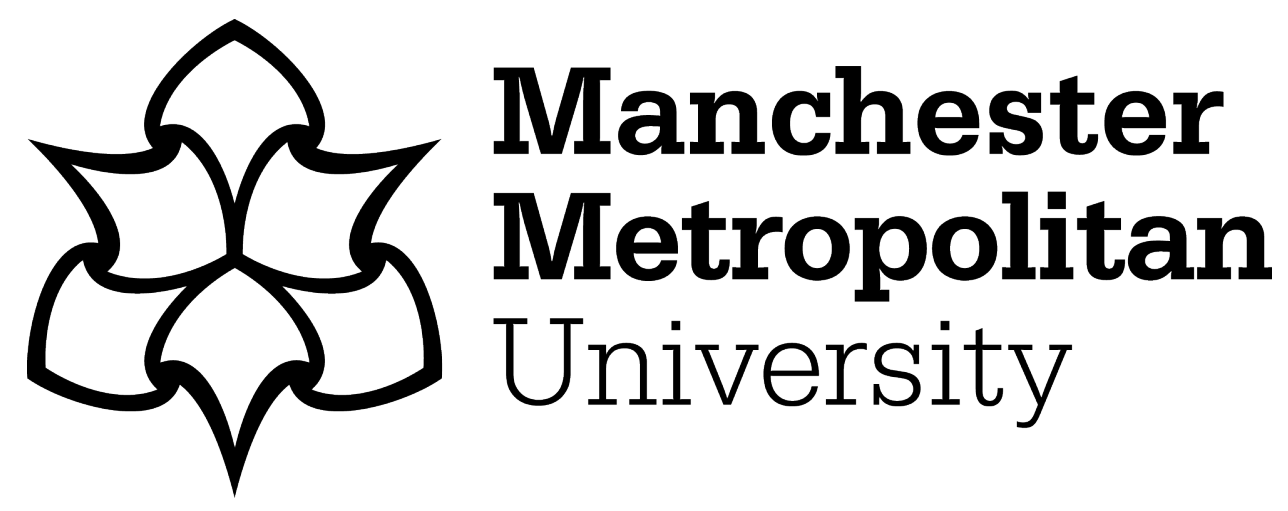

Wilson-Nieuwenhuis, JST, Dempsey-Hibbert, N, Liauw, CM and Whitehead, KA (2017) Surface modification of platelet concentrate bags to reduce biofilm formation and transfusion sepsis. Colloids and Surfaces B: Biointerfaces, 160. pp. 126-135. ISSN 0927-7765

Downloaded from: https://e-space.mmu.ac.uk/619006/

Version: Accepted Version

Publisher: Elsevier

DOI: https://doi.org/10.1016/j.colsurfb.2017.09.019

Usage rights: Creative Commons: Attribution-Noncommercial-No Derivative Works 4.0

Please cite the published version 


\title{
Surface modification of platelet concentrate bags to reduce biofilm formation and
}

\section{transfusion sepsis.}

Joels S. T. Wilson-Nieuwenhuis, Nina Dempsey-Hibbert, Christopher M. Liauw, and Kathryn A. Whitehead*

School of Healthcare Sciences, Manchester Metropolitan University, Manchester M1 5GD UK.

*Corresponding Author: K. A. Whitehead, School of Healthcare Science, Manchester Metropolitan University, UK. Tel: +441612471157 E-mail: $\underline{\text { K.A.Whitehead@mmu.ac.uk }}$

\begin{abstract}
Bacterial contamination of blood products poses a major risk in transfusion medicine, including transfusions involving platelet products. Although testing systems are in place for routine screening of platelet units, the formation of bacterial biofilms in such units may decrease the likelihood that bacteria will be detected. This work determined the surface properties of p-PVC platelet concentrate bags and investigated how these characteristics influenced biofilm formation. Serratia marcescens and Staphylococcus epidermidis, two species commonly implicated in platelet contamination, were used to study biofilm growth. The platelet concentrate bags were physically flattened to determine if reducing the surface roughness altered biofilm formation. The results demonstrated that the flattening process of the platelet bags affected the chemistry of the surface and reduced the surface hydrophobicity. Flattening of the surfaces resulted in a reduction in biofilm formation for both species after 5 days, with S. marcescens demonstrating a greater reduction. However, there was no significant difference between the smooth and flat surfaces following 7 days' incubation for $S$. marcescens and no significant differences between any of the surfaces following 7 days' incubation for $S$. epidermidis. The results suggest that flattening the p-PVC surfaces may limit potential biofilm
\end{abstract}


formation for the current duration of platelet storage time of 5 days. It is hoped that this work will enhance the understanding of how surface properties influence the development of microbial biofilms in platelet concentrate bags in order to devise a solution to discourage biofilm formation.

Keywords: Biofilms; MATH; Physicochemistry; Chemistry; Topography; Surface.

\section{Introduction}

Bacterial contamination of blood products poses one of the biggest risks of transfusion medicine. ${ }^{1}$ This contamination is most commonly associated with transfusion of platelet concentrates (PC). This occurs in part due to the storage conditions within the blood bank used to maintain the platelets, which inadvertently provide ideal conditions for bacterial growth and proliferation. It is reported that approximately 1 in 2000-5000 PCs are contaminated. ${ }^{2-4}$ Whilst the reported incidence of culture confirmed sepsis is relatively low, at around 1 in 100,000 , a higher incidence rate of 1 in 25,000 has been estimated, with higher rates likely due to under reporting of transfusion-related sepsis. ${ }^{1,2}$ Given that PC's are frequently administered to immunocompromised patients such as those with major medical issues in oncology, haematology, paediatric and bone marrow transplant patients, bacterial contamination and resultant sepsis can prove fatal. ${ }^{5}$ The mandatory use of bacterial detection systems within the national blood banks, such as the BacT/Alert microbial detection system minimise the likelihood of transfusing a contaminated unit. Yet, whilst these systems are extremely valuable, occasionally false negatives can occur due to low initial bacterial concentration in the PCs or due to the formation of bacterial biofilms within the PCs during storage. ${ }^{6,7}$ Even with these systems in places, storage time is not always extended from the 5-day safer period to the longer 7-day storage period. ${ }^{1,6}$ 
Whilst aseptic techniques are used during the processing of blood products, three main sources of contamination exist: the venepuncture site during phlebotomy, transient donor bacteraemia and contamination during PC processing. ${ }^{1,8}$ Of these, the most common contaminants are typically skin flora surrounding the venepuncture site, contaminating the blood during collection. ${ }^{8}$ Most isolated contaminants are Gram-positive commensal skin flora species, with the two most commonly identified bacteria being Staphylococcus epidermidis (often only identified as a coagulase-negative staphylococci) or Propionibacterium acnes. ${ }^{8-10}$ Whilst it is more common for contaminants to be Gram-positive, Gram-negative bacteria are responsible for $60 \%-80 \%$ of transfusion septic fatalities. ${ }^{5,11}$ Gram-negative species such Serratia spp, Escherichia coli, Salmonella spp and Enterobacter spp have all been implicated in severe adverse transfusion reactions. ${ }^{11}$ Of these, Serratia spp has been shown as being able to remain culture negative even after 9 days of storage, leading to several severe or fatal septic reactions. ${ }^{12}$ Biofilms form when individual bacterial cells adhere to a surface and to other bacterial cells, becoming embedded in a matrix of extracellular polymeric substance (EPS) in a complex and multifactorial process. ${ }^{13-15}$ The EPS is usually comprised of mostly polysaccharides with some DNA and proteins. ${ }^{16}$ Biofilm formation enables the bacteria to alter their gene expression whilst also altering cell growth, making the bacteria much harder for screening systems to detect. ${ }^{13,17}$ Further, if the bacteria are adhered to the surface of the platelet bag in the form of biofilms then less cells may be in planktonic form within the unit and therefore are not collected into the aliquot for testing, leading to false negatives. ${ }^{18}$

Initially bacteria are weakly adhered to a surface via Lifshitz Van der Waals forces, after which stronger adhesion is formed due to bacterial cell adhesion structures. ${ }^{15}$ Lifshitz Van der Waals forces are properties of both the bacteria and the surfaces, and understanding their interactions can elucidate how the bacteria interact at the cell:surface interface. By altering the surface to 
produce changes in the surface properties, it is possible to alter how bacteria interact with a surface and potentially reduce bacterial adherence. As such, whilst it may be possible to develop more sensitive detection systems, modifying the platelet bag surfaces in a way so that bacterial cells are either unable or take longer to adhere to the platelet bag surface could play a role in reducing false negatives in already established systems.

An approach to reduce initial surface contamination, which may lead to a subsequent reduction in biofilm formation, is to modify the substratum surface topography. ${ }^{19}$ Although a number of studies have been carried out on the effect of surface topography on microbial retention, findings are often conflicting especially when macro topography $(>10 \mu \mathrm{m})$, micro topography $(<10 \mu \mathrm{m}-0.5 \mu \mathrm{m})$ and nano topographies $(<0.5 \mu \mathrm{m})$ may be present, all of which may affect initial conditioning film and bacterial attachment. ${ }^{20}$

It is proposed that surface modification of the p-PVC platelet bags could reduce bacterial attachment, which would have two major advantages; (1) bacteria would be planktonic and therefore more likely to be collected in the testing aliquot for BacT/Alert screening, (2) bacteria would be unable to increase their virulence properties and slow their growth rate as occurs upon biofilm formation, hence increasing the likelihood of bacterial detection.

The aim of this work was to determine if a reduction in surface roughness of p-PVC platelet transfusion bag surfaces reduced the formation of $S$. marcescens or $S$. epidermidis biofilms.

\section{Methods}

\section{Coupon Preparation}

\section{Unmodified Coupons}

Plasticized poly(vinyl chloride) ( $\mathrm{p}$-PVC) platelet storage bags were obtained from Terumo BCT (USA). Coupons of $11 \mathrm{~mm}$ in diameter were punched from p-PVC platelet bags using an $11 \mathrm{~mm}$ disc punch (Agar scientific, UK) and the coupons were then sterilised. 


\section{Flattened Coupons}

Strips of p-PVC were cut from whole platelet bags, $150 \mathrm{~mm}$ x $25 \mathrm{~mm}$, and were placed between two sheets of kapton. A template made of polyethylene terephthalate (PET) was used to ensure the p-PVC was not flattened beyond the depth of the PET for consistency. This was placed in between stainless steel sheets, which was subsequently placed between two plates of steel which had been pre-heated to $150{ }^{\circ} \mathrm{C}$ in the hot press. The p-PVC / PET / Kapton and stainless steel sheets were placed into the hot press and 10 tonnes pressure was applied at $150{ }^{\circ} \mathrm{C}$ for 10 min. The plates were transferred to a cold press and cooled with 10 tonnes of pressure for 10 min. Circular coupons (11 mm diameter) were punched out of the flattened strips; these were sterilised immediately.

\section{Sterilisation of Coupons}

Coupons were placed into a $30 \mathrm{~mL}$ sterile universal containing $70 \%(\mathrm{v} / \mathrm{v})$ ethanol and vortexed for one min. The coupons were then soaked for $15 \mathrm{~min}$ in the ethanol. The ethanol was removed and the coupons were aseptically transferred to a sterile Petri dish containing sterile distilled water $\left(\mathrm{dH}_{2} \mathrm{O}\right)$ to remove the ethanol before being aseptically moved across to another sterile Petri dish containing sterile $\mathrm{dH}_{2} \mathrm{O}$. The washing sequence was performed in triplicate to ensure all the excess ethanol was removed before the coupons were air dried in a class II microbiological cabinet.

\section{Scanning Electron Microscopy}

An overnight culture was prepared and the washed bacterial inoculum was diluted to an optical density (OD) of 1.0 at $540 \mathrm{~nm}$. Ten microliters of bacterial inoculum was pipetted onto a coupon and dried in a class II cabinet for $1 \mathrm{~h}$ before being processed by placing into $4 \%$ glutaraldehyde (made up in phosphate buffered saline) overnight. The coupons were removed from the glutaraldehyde using tweezers and rinsed with sterile $\mathrm{dH}_{2} \mathrm{O}$ to remove the remaining 
solvent. The coupons were dried in a fume hood for $1 \mathrm{~h}$ before an ethanol gradient of $10 \%, 30$ $\%, 50 \%, 70 \%, 90 \%$ and $100 \%$ made up from absolute ethanol diluted with sterile $\mathrm{dH}_{2} \mathrm{O}$ was performed. Each coupon was left in each ethanol concentration for 10 min moving from the lowest ethanol concentration to the greatest. Once removed from the $100 \%$ ethanol solution, the coupons were placed into a desiccator and were later attached to SEM stubs with carbon tabs prior to being sputter coated with a gold and palladium coating (Model: SC7640, Polaron, $\mathrm{Au} / \mathrm{Pd}$ target, deposition time: $1.5 \mathrm{~min}$ ) before being stored in a desiccator until imaged.

\section{Surface Roughness and Optical Surface Profiles}

Surface roughness $\left(S_{a}\right)$ values were calculated from surface profiles measured using a ZeGage 3D Optical Surface Profiler (Zygo, USA) for all p-PVC coupons. Measurements were taken using $50 \mathrm{x}$ magnification with a scanning distance of $50 \mu \mathrm{m}$ from the centre position $(\mathrm{n}=3)$. Attenuated Total Reflection-Fourier Transform Infrared Spectroscopy (ATR-FTIR)

ATR-FTIR was used to determine the molecular structures and chemical bonds of the untreated and modified p-PVC (Nicolet 380 FTIR with a Smart iTR attachment, Thermo Scientific, UK). Background spectra was captured prior to each measurement and spectra were acquired at room temperature using Omnic 5.2 software with each run made up of 16 scans and a resolution of $4 \mathrm{~cm}^{-1}$. Analysis of each sample was performed in triplicate and the average spectra were reported $(n=3)$.

\section{Physicochemistry of surfaces}

Contact angles $(\theta)$ using HPLC grade water (BDH, UK), ethylene glycol or dioodomethane (Alfa Aesar, USA) were measured with a MobileDrop goniometer (Krüss GMBH, Germany). Both advancing and receding angles were determined, with five measurements of each chemical on each sample taken $(n=10)$. Fresh coupons were used for each solvent to ensure there was no cross contamination of solvents on the surfaces. The method of Van Oss et al. ${ }^{21}$ 
was used for calculating the surface energy $\left(\gamma_{S}^{S E}\right)$ of the films from these measurements, according to the following equation:

$$
\left(1+\gamma_{l}\right) \cos \theta=2\left(\sqrt{\gamma_{s}^{L W} \gamma_{l}^{L W}}+\sqrt{\gamma_{s}^{A} \gamma_{l}^{B}}+\sqrt{\gamma_{s}^{B} \gamma_{l}^{A}}\right)
$$

where the subscripts $s$ and $l$ denote the surface energy of the solid and liquid respectively. The superscript $L W$ denotes the Lifshitz-van der Waals components of the surface energy, and the superscripts $A$ and $B$ denote the Lewis acid and Lewis base parameters of the surface energy. The acid and base terms can be combined into the Lewis acid base (superscript $A B$ ) component of the surface energy:

$$
\gamma_{i}^{A B}=2 \sqrt{\gamma_{i}^{A} \gamma_{i}^{B}}
$$

Subsequently the overall surface energy was calculated as the sum of the Lifshitz-van der Waals and Lewis acid base components:

$$
\gamma_{i}=\gamma_{i}^{L W}+\gamma_{i}^{A B}
$$

The components of the surface energy were then used to assess the hydrophobicity, or Gibbs free energy of attraction between the surface and liquid (surface energies are denoted by subscript $w$ ), and were calculated using the following 22 :

$$
\Delta G_{s w}=-2\left(\left(\sqrt{\gamma_{s}^{L W}}-\sqrt{\gamma_{l}^{L W}}\right)^{2}+2\left(\sqrt{\gamma_{s}^{a} \gamma_{s}^{b}}+\sqrt{\gamma_{l}^{a} \gamma_{l}^{b}}-\sqrt{\gamma_{s}^{a} \gamma_{l}^{b}}-\sqrt{\gamma_{l}^{a} \gamma_{s}^{b}}\right)\right)
$$

Tensile Strength Determination 
Tensile strength of the PVC was determined using a Hounsfield H10KS tensometer running Qmat 5.53. Samples were run with a $4 \mathrm{~mm}$ width and a $200 \mathrm{~mm} / \mathrm{min}$ speed $(\mathrm{n}=5)$.

\section{Bacterial Growth Conditions}

Strains of Serratia marcescens (NCTC 9741) and Staphylococcus epidermidis (DSM 28319) were obtained from frozen pure culture stock, plated onto tryptone soya agar (TSA) (Oxoid, UK) and incubated at $37^{\circ} \mathrm{C}$ overnight. New plates were streaked from freezer stock every four weeks to ensure the continuity of the bacteria was maintained for all experiments, with streaked plates stored at $4{ }^{\circ} \mathrm{C}$. A single colony was removed from the agar plate and inoculated into a volume $(10 \mathrm{~mL})$ of sterile tryptone soya broth (TSB) (Oxoid, UK) which was incubated overnight at $37^{\circ} \mathrm{C}$ with shaking $(150 \mathrm{rpm})$. The bacterial culture was centrifuged at $2210 \mathrm{~g}$ for $12 \mathrm{~min}$, the supernatant removed and the cells washed with $10 \mathrm{~mL}$ of sterile $\mathrm{dH}_{2} \mathrm{O}$ before repeating. The cells were re-suspended in sterile $\mathrm{dH}_{2} \mathrm{O}$ and diluted to an $\mathrm{OD}$ of $1.0( \pm 5 \%)$ at $540 \mathrm{~nm}$ using a spectrophotometer (Jenway 6305, UK). A serial dilution with spread plates was performed in duplicate with three separate bacterial broth cultures to obtain $1.25 \times 10^{9}$ colony forming units per $\mathrm{mL}\left(\mathrm{CFU} \mathrm{mL} \mathrm{m}^{-1}\right)$ for $S$. marcescens and $1.44 \times 10^{8} \mathrm{CFU} \mathrm{mL}^{-1}$ for $S$. epidermidis at an OD of 1.0 at $540 \mathrm{~nm}$.

\section{Biofilm formation}

A $1.8 \mathrm{~mL}$ volume of sterile broth was added to each well of a sterile 12-well plate (Nunc NonTreated Multidishes, Thermo Fisher Scientific, UK) along with a sterilised p-PVC coupon, 11 $\mathrm{mm}$ in diameter, test side of the surface face up. The reverse end of a sterile swab was used to push the coupon to the bottom of the well. The 12 well plates were left at room temperature overnight to check for any contaminant growth and to check that all coupons were fully sterilised. An overnight culture was prepared and diluted to obtain $1.0 \times 10^{8} \mathrm{CFU} \mathrm{mL}^{-1}$. Two hundred microliters of the bacterial suspension was added to the appropriate wells to give a 
working concentration of $1.0 \times 10^{7} \mathrm{CFU} \mathrm{mL}^{-1}$. The 12 well plates were parafilmed to prevent the media from evaporating from the plates. The plates were incubated at $22{ }^{\circ} \mathrm{C}$ for either 5 or 7 days with gentle shaking $(68 \mathrm{rpm})$. Following incubation, all the media in each well was removed by pipetting, leaving just the coupon behind and the wells containing the coupons were washed by adding $2 \mathrm{~mL}$ of sterile $\mathrm{dH}_{2} \mathrm{O}$ to each well; carefully against the side of the well so as not to disturb the biofilm formed on each coupon. The liquid was gently swirled around the wells manually for $5 \mathrm{~s}$ before pipetting out the liquid to remove any unbound planktonic cells. The 12 well plates and coupons were air dried in a class II cabinet for $1 \mathrm{~h}$.

\section{Crystal Violet Assay}

One millilitre of $0.03 \% \mathrm{w} / \mathrm{v}$ crystal violet solution was added to each well following drying, ensuring full coupon coverage, and left for $30 \mathrm{~min}$. After the allotted time, the stain was pipetted out of each well and $2 \mathrm{~mL}$ of sterile $\mathrm{dH}_{2} \mathrm{O}$ was added and manually gently swirled around for $10 \mathrm{~s}$ to remove the excess stain. This was repeated once and the coupons were removed after the second time and transferred to a fresh 12 well plate. To each well in the new plate, $2 \mathrm{~mL}$ of $33 \%(\mathrm{v} / \mathrm{v})$ glacial acetic acid solution was added and left for $15 \mathrm{~min}$ with manual agitation every $5 \mathrm{~min}$ to elute the bound crystal violet from the biofilm. The absorbance of the eluted stain in the glacial acetic acid was measured at $590 \mathrm{~nm}$ to determine the optical density, thus quantifying biofilm growth. The absorbance value obtained was doubled to convert it to OD per mL. When the absorbance was too high to be read, the remaining $1 \mathrm{~mL}$ in the well was diluted down with another $1 \mathrm{~mL}$ of $33 \%(\mathrm{v} / \mathrm{v})$ glacial acetic acid solution and measured, with values obtained multiplied by four to account for the dilution. $(n=6)$

Microbial Adhesion to Hydrocarbons (MATH) Assay

Cultures were grown at $37{ }^{\circ} \mathrm{C}$ overnight in TSB. Bacterial cells were harvested via centrifugation at $2210 \mathrm{~g}$ for $12 \mathrm{~min}$ and then washed 3 times using PUM buffer $\mathrm{pH} 7.1$ (PUM 
buffer; $\mathrm{K}_{2} \mathrm{HPO}_{4} .3 \mathrm{H}_{2} \mathrm{O}$ 22.2; $\mathrm{KH}_{2} \mathrm{PO}_{4}$ 7.26; urea 1.8; $\mathrm{MgSO}_{4} .7 \mathrm{H}_{2} \mathrm{O} 0.2 \mathrm{~g} / \mathrm{L}$ ) and re-suspended to an OD 1.0 at $400 \mathrm{~nm}$. A $1.5 \mathrm{~mL}$ volume of washed cells suspended in PUM buffer was added to a round bottomed test tube $15 \mathrm{~mm}$ in diameter. A $250 \mu \mathrm{L}$ volume of one of the test liquids (Chloroform; Hexadecane; Ethyl Acetate or Decane (BDH, UK)) was added to the suspension. Suspensions were incubated at $37^{\circ} \mathrm{C}$ for $10 \mathrm{~min}$ to equilibrate. The test suspension was vortexed for $2 \mathrm{~min}$ before re-incubation for $30 \mathrm{~min}$ at $37{ }^{\circ} \mathrm{C}$ to allow separation of the lower aqueous phase. The lower aqueous phase was removed from the test tube and the OD determined at 400 $\mathrm{nm}$. This was used with a calculation developed by Rosenberg et al. ${ }^{23}$ to determine cell surface hydrophobicity;

$$
\text { adhesion }=\left(\frac{1-A}{A \varnothing}\right) \times 100
$$

Where $A ø$ was the optical density of the microbial suspension when measured at $400 \mathrm{~nm}$ before adding test chemical and $A$ was the optical density measured at $400 \mathrm{~nm}$ of the extracted lower aqueous phase after mixing with the hydrocarbon. $(\mathrm{n}=3)$

\section{Statistics}

All results were presented as mean \pm standard deviation (SD) for tables or \pm standard error (SE) for the figures. Mean values were compared using analysis of variance (ANOVA) to determine significant differences between mean values at the $95 \%$ confidence level $(p<0.05)$.

\section{Results}

\section{Surface analysis}

Upon initial analysis of the bags, it was determined that they were made of two sheets of pPVC melded together. The analysis of the PC bags was carried out on the inside faces of the bags against which the PCs come into contact. SEM images demonstrated that one inside face of the p-PVC had a diamond patterned surface, which showed roughened features (rough surface) (Fig. 1a.). The rough surface showed pits along the edges of the diamond imprints of 
varying sizes. In comparison to this, the other inward facing side of the p-PVC polymer demonstrated a smoother, more featureless surface (smooth surface) (Fig. 1c.). Due to the unexpected surface features, flattening of the surfaces was performed to remove any surface features and determine whether this was enough to reduce biofilm growth. Post flattening of the p-PVC, the surface was demonstrated to be smoother still and without any discernible surface features (flat surface) (Fig. 1e).

Following quantification of the surface roughness, optical surface profiling demonstrated that the rough surface inside of the platelet bag had the greatest levels of differing surface topography (Fig. 2a). The mean surface roughness $\left(S_{a}\right)$ of the rough surface varied between the diamond bottom, ridges and the sides of the diamonds which were demonstrated as having pits. A statistically significant reduction in $S_{a}$ value was observed from the rough surface ( 3549.8 $\mathrm{nm})$ to the smooth surface $(1021.2 \mathrm{~nm})$ and a further reduction was observed on the flattened surface $(108.1 \mathrm{~nm})$.

The ATR-FTIR spectra of the surfaces were dominated by the major absorptions expected in p-PVC (Fig. 2b). The most dominant were C-H stretching (centred at ca $2900 \mathrm{~cm}^{-1}$ ), ester carbonyl stretching from the plasticiser $\left(1740 \mathrm{~cm}^{-1}\right)$ and $\mathrm{C}-\mathrm{O}$ bending of the plasticiser ester $\left(1170 \mathrm{~cm}^{-1}\right)$. The C-Cl stretching vibration from the PVC itself at ca. $690 \mathrm{~cm}^{-1}$ was also present. Two very small absorptions appeared between the phthalate ester carbonyl stretch and the C$\mathrm{H}$ bending vibration of the PVC / plasticiser at $1458 \mathrm{~cm}^{-1}$ (see Fig. 2 inset). The smooth unmodified surface showed two small absorption peaks at $1576 \mathrm{~cm}^{-1}$ and $1541 \mathrm{~cm}^{-1}$, however, on the rough unmodified surface only one peak at $1539 \mathrm{~cm}^{-1}$ was evident. Interestingly, both peaks were absent on the flattened surface. The peak positions match the antisymmetric $v_{\mathrm{as}} \mathrm{COO}^{-}$stretching vibration of carboxylate groups in unidendate $\left(1577-1575 \mathrm{~cm}^{-1}\right)$ and bidendate $\left(1544-1540 \mathrm{~cm}^{-1}\right)$ coordination with calcium. ${ }^{25}$ The carboxylate carbonyl absorptions 
for the zinc stearate were simpler, just a single peak at ca $1540 \mathrm{~cm}^{-1} \cdot{ }^{26}$ A schematic representation of the possible adsorbed structure of calcium stearate on the unmodified p-PVC surfaces is demonstrated indicating the presence of calcium/zinc stearates on the surface were present for the smooth, and to a degree the rough surfaces (Fig. 3a). However, after the flattening process the two carboxylate carbonyl absorptions were no longer present, suggesting that during the flattening process the calcium stearate either diffused more deeply into the pPVC or preferentially adsorbed onto the kapton separating sheets (Fig. 3b).

Physicochemistry measurements between the smooth and rough surfaces demonstrated that there were no significant differences in the results (Table. 1). An increase in the Gibbs Free $(\Delta G)$ energy demonstrated that flattening of the surfaces resulted in the surface becoming less hydrophobic, and an increase in the overall surface energy $\left(\gamma_{s}\right)$. However, the flat modified surface maintained similar Lifschitz van der Waals force $\left(\gamma_{s} L W\right)$ values as the unmodified (smooth and rough) surfaces. The higher base energy $\left(\gamma_{s^{-}}\right)$on all the surfaces demonstrated that the surfaces were electron donating rather than electron accepting. Flattening the p-PVC resulted in an increase in both the acid $\left(\gamma_{s}+\right)$ and base $\left(\gamma_{s^{-}}\right)$energies demonstrating the surfaces' ability to donate and accept electrons had both increased.

Tensile strength measurements of both surfaces determined that there was no significant difference between the average tensile strength of the unmodified surface (15.679 Mpa) and the flattened surface $(15.145 \mathrm{Mpa})$ apart from the higher variability apparent for the modified surface. Further, there was also no significant difference between the elongation percentage for the unmodified surface $(329.760 \%)$ and the flattened surface $(358.720 \%)$ (Table 2$)$.

\section{Microbiology}

SEM of the surfaces with the bacteria demonstrated that the density of $S$. marcescens and $S$. epidermidis was similar on all the surfaces (Fig. 1). The bacteria were observed to be clumped 
in and around the pits of the rough surface with fewer cells spread around the other surface features (Fig. 1a and b). The number of cells present on the smooth surface was significantly reduced, and most cells formed small groups (Fig. 1c and d). On the flat surface, both species demonstrated very low coverage with only a few cells visible (Fig. 1e and 1f).

The MATH assay for S. marcescens (Fig. 4a) demonstrated a low affinity for the apolar nalkanes decane $(6.33 \%)$ and hexadecane $(5.24 \%)$, whilst having a moderate affinity for the acidic (Lewis-acid) solvent chloroform (43.97\%) and the basic (Lewis-base) solvent ethyl acetate $(50.12 \%)$. Pairs were chosen as having one polar and one non-polar liquid, both with similar Lifschitz van der Waals forces. ${ }^{31}$ The extremely low affinity $(<10 \%)$ towards both non-polar hydrocarbons decane and hexadecane determined that $S$. marcescens was highly hydrophilic, which was supported by the bacteria having a greater affinity to the polar solvents chloroform and ethyl acetate. ${ }^{28-30}$ The stronger affinity for both of the polar solvents (chloroform and ethyl acetate) when compared with their non-polar counterpart (hexadecane with chloroform and decane with ethyl acetate) further indicated that $S$. marcescens was both a moderate electron donor and a moderate electron acceptor. ${ }^{29}$ However, when compared in their pairs (chloroform and hexadecane against ethyl acetate and decane), the value for ethyl acetate and decane was higher, which demonstrated that the bacteria were better electron donors than acceptors. ${ }^{29}$ This was further supported by the higher affinity to chloroform than to hexadecane. ${ }^{31}$

In contrast, S. epidermidis' MATH assay results (Fig. 4b) were significantly different to that of $S$. marcescens, demonstrating a high affinity to the apolar n-alkanes decane $(98.21 \%)$ and hexadecane (97.76\%) whilst also having a high affinity to the acidic solvent chloroform (98.44 $\%)$. The high affinity (>55.00\%) to both non-polar hydrocarbons decane and hexadecane determined that $S$. epidermidis was highly hydrophobic. This was supported by the higher 
combined affinity to the non-polar hydrocarbons (decane and hexadecane) when compared against the polar hydrocarbons (chloroform and ethyl acetate). The significantly higher affinity of S. epidermidis to the acidic solvent chloroform compared to the basic solvent ethyl acetate $(30.67 \%)$ indicated that the bacteria were strong electron donors. S. epidermidis as an electron donor was further supported by a higher combined value of chloroform and hexadecane compared to ethyl acetate and decane. S. epidermidis also had a moderate affinity to the basic solvent ethyl acetate indicating that whilst it was a strong electron donor it also had moderate electron accepting properties. This determined that S. epidermidis was highly hydrophobic and was a strong electron donor, with lesser electron accepting properties.

Biofilm growth of both $S$. marcescens and $S$. epidermidis following incubation in platelet storage conditions $\left(22^{\circ} \mathrm{C}\right)$ on the p-PVC for 5 or 7 days was assessed using a crystal violet assay (Fig. 5). Following 5 days' incubation, $S$. marcescens demonstrated a significant decrease in the amount of biofilm formed on the flattened (1.75) surface when compared to the rough (3.26) or smooth (2.94) surfaces (Fig. 5a). Whilst a decrease in the amount of growth on the flattened (2.60) surface compared to with that on the rough (3.66) surface was observed at day 7, it was less apparent than after 5 days, and no significant decrease was observed between the smooth and flat surfaces after 7 days (Fig. 5a). Similarly, S. epidermidis demonstrated a reduced growth on the flat (1.06) surface compared to the rough (1.96) and smooth (1.42) surfaces after 5 days of incubation, despite demonstrating significantly less growth overall (Fig. 5b). However, after 7 days' incubation there was no significant difference between the rough (2.13), smooth (1.94) or flat (2.04) surfaces (Fig. 5b).

\section{Discussion}

Surface Analysis 
The surface properties of PC bags were characterised in order to determine the effect on biofilm formation. The microbial pathogens $S$. marcescens and S. epidermidis were used in the study as both species are regularly identified in contaminated PCs. The platelet bag surfaces were also flattened to determine whether alterations to the surface could potentially reduce biofilm growth. Observations of the topography of the surfaces via SEM and of biofilm growth, as quantified via crystal violet assay, demonstrated that the rougher surface features of the p-PVC platelet bag typically accumulated the most biofilm mass. This demonstrated a bacterial preference for a rougher surface to grow on, which may be due to an increase in surface contact area between the surface and the bacteria, increasing the strength of the initial adherence. The preference of bacteria for surfaces with defined features has previously been shown, where differing surface features altered bacterial retention. ${ }^{19,32}$ The surface roughness did not appear to affect the surface energies, as the surface energy properties of both the rough and smooth surfaces were similar. However, the flattened surface, which demonstrated no surface features did present differences in its surface energies, indicating that the flattening procedure changed the surface energy. The changes observed in the surface energy of the flattened surface led to the surface becoming less hydrophobic as well as increasing its overall ability to accept and donate electrons, whilst maintaining a preference for accepting electrons. These changes may reduce or increase bacterial adherence to the flattened surface, depending on the surface energy components of the bacteria themselves.

Analysis of the surface chemistry via ATR-FTIR demonstrated that most of the spectra for all the surfaces were similar. Whilst the C-CL stretching vibration of PVC would be a strong band in non-plasticised PVC, the high level of plasticiser in the samples caused absorptions from the latter to dominate the spectrum. Aromatic C-H stretching and deformation absorptions (3060 $3100 \mathrm{~cm}^{-1}$ and $1600-1580 \mathrm{~cm}^{-1}$, respectively) were absent from the spectrum confirming that 
a phthalate plasticiser had not been used in this particular platelet bag formulation. Absence of phthalates was further supported by the specific wavenumber of the ester carbonyl stretching absorption; phthalate carbonyl groups absorb at ca. $1730 \mathrm{~cm}^{-1}$, whereas adipate and sebecate carbonyl groups absorb at ca $1740 \mathrm{~cm}^{-1} .^{24}$

The two carboxylate carbonyl peaks $\left(1576\right.$ and $\left.1541 \mathrm{~cm}^{-1}\right)$, indicating presence of calcium / zinc stearates on the surface and / or within ca. $1.8 \mu \mathrm{m}$ of the surface, were present for the smooth, and to a degree the rough surfaces. However, after the flattening process the two carboxylate carbonyl absorptions were no longer present, suggesting that during the flattening process the calcium stearate either diffused more deeply (i.e., deeper than ca $1.8 \mu \mathrm{m}$ ) into the p-PVC or was preferentially adsorbed on to the polyester separating sheets, either way, calcium / zinc stearate could no longer be resolved by ATR-FTIR. An identical observation has been made by Bodecchi et al. ${ }^{33}$ in ATR-FTIR studies on plasticised PVC that had been sterilised by $\beta$-irradiation, where it was argued that the stearate diffused further into the p-PVC. Combinations of calcium and zinc stearates have been reported to form complexes during the stabilisation of $\mathrm{PVC},{ }^{34}$ with the combined carboxylate carbonyl stretching vibrations of the complex resulting in an absorption at $1600 \mathrm{~cm}^{-1}$, but no such absorption was evident. This indicated that the stearates had been removed or diffused deeper into the substrate, rather than becoming complexed / combined as a result of elevated temperatures experienced by the pPVC during the flattening operation. The spectrum of the rough surface was noisier than the smooth and flat surface due to the rough surface having an impaired contact with the internal reflection element of the ATR accessory.

The contact angle measurements demonstrated that the unmodified surfaces had lower surface energies than the flattened surface, and this observation indicated that a fraction of the stearates had bloomed to the surface of the unmodified substrates; the increase in surface energy of the 
flattened substrate is corroborated by the absence of stearates on this sample. As the p-PVC had a relatively polar surface it may be that the bloomed calcium / zinc stearates were adsorbed with the carboxylate groups facing the surface, leaving the stearyl $\left(\mathrm{C}_{17} \mathrm{H}_{35}\right)$ tails pointing away from the surface. The latter may account for the unidentate form of calcium stearate, absorbing at ca. $1576 \mathrm{~cm}^{-1}$. If the local surface concentration of calcium stearate was high enough, the stearyl tails of the bidentate form (absorbing at ca. $1541 \mathrm{~cm}^{-1}$ ) in the form of a bi-layer with $\mathrm{Ca}^{2+}$ ions in between, could incorporate the unidentate forms in wax-like self-assembled surface structures. ${ }^{35}$ Such structures could have contributed to the reduced surface energy of the unmodified surfaces. The marginally higher values of $\gamma^{-}, \gamma^{+}$and $\gamma_{\mathrm{s}}{ }^{\mathrm{AB}}$ obtained for the smooth unmodified surface, relative to the rough unmodified surface, may have been due to incorporation of some unidentate carboxylate, with the carboxylate group pointing away from the p-PVC, within the self-assembled structures. The rough unmodified surface showed only one carboxylate absorption at $1539 \mathrm{~cm}^{-1}$, indicating the presence of bidentate calcium stearate, possibly with a small amount of zinc stearate. However, a uniform monolayer of stearate composed of stearyl chains, pointing away from the substrate in a self-assembled array, will have a very low surface energy of $22-24 \mathrm{~mJ} / \mathrm{m}^{2} 36$, and the latter here is clearly not the case and the implication is that the surface coverage with calcium / zinc stearate was not uniform. It may be that the stearates exist as micron-scale patches on the surface of the p-PVC.

\section{Microbiology}

When observing biofilm growth of both bacterial species on the smooth and flattened surfaces, and comparing this with growth observed on the rough surface, it was demonstrated that there was significantly more growth on the rough surface. The only exception to this was after 7 day's incubation with $S$. epidermidis when there was no significant difference between the surfaces. Since the chemistry and physicochemistry of the rough and smooth surfaces were the 
same, this can only be due to a topographical effect with respect to the smooth surface. The similar growth on all the surfaces after 7 day's incubation with $S$. epidermidis may have been caused by a build-up of conditioning film and cells after the 5 days which meant that any surface topography, chemistry or physicochemistry effects on biofilm growth were negated. The effect of flattening the surface resulted in the most pronounced biofilm reduction with $S$. marcescens after 5 days. It is suggested that for $S$. marcescens, which demonstrated moderate electron donor and accepting properties, as well as highly hydrophilic properties, the reduction in hydrophobicity of the flattened surface reduced initial adherence of the bacteria to the surface. ${ }^{28-31}$ However, the reduced biofilm growth could also be due to the lack of features present on the flattened surface which reduced surface area contact between the bacteria and the surface. A combination of both factors is most likely to be the cause of the lowered retention of $S$. marcescens to the flattened surface. However, it is difficult to determine which surface parameter had the most influence.

With respect to $S$. epidermidis, this organism was found to be highly hydrophobic and have strong electron donor properties. Therefore, it would not be unreasonable to assume that on the flattened surface which has reduced hydrophobicity and electron accepting properties, there would be an increase in total biofilm mass. ${ }^{28-30,37}$ However, our results demonstrated initial decreased biofilm growth on the flattened surface when compared to the rough after 5 days, which may be attributed to the lack of surface features.

Although data exists to support the theory that bacteria, which are generally negatively charged, will preferentially adhere to negatively charged surfaces, there are conflicting results in this area due to assays being carried out in a number of different ways and under different environmental conditions. ${ }^{28,38,39}$ However, it is clear from the present study that each reduction in surface topography resulted in a reduction in biofilm formation on each surface for both 
bacterial species after 5 days incubation. However there was no significant differences between any of the surfaces following 7 days' incubation for S. epidermidis or between the smooth and flat surfaces following 7 days' incubation for $S$. marcescens. Over time, it appeared that the reduction of biofilm formation between the unmodified surfaces and the flattened surface was lessened as the reduction in growth was much greater at the 5-day point than what was observed after 7 days. This may be due to a build-up of adhered cells to the surfaces, which would gradually mask the underlying surface properties and allow adherence of further cells.

There is conflicting evidence regarding how significant the surface properties such as the roughness and physicochemistry are in determining bacterial retention, and hence biofilm formation. It has previously been determined by Katsikogianni et al. that under the conditions of flow on p-PVC surfaces, bacterial adhesion was influenced by the surface roughness. ${ }^{40}$ However, it has also been demonstrated that p-PVC surface colonisation by Pseudomonas aeruginosa and S. epidermidis was independent of surface roughness and wettability. ${ }^{41}$ Furthermore, previous work completed by our group has demonstrated that whilst hydrophobic bacteria tend to adhere more to a hydrophilic surface and vice versa, some bacterial species can adhere better to a surface that has the same wettability. ${ }^{39}$

\section{Conclusion}

The results demonstrated that by reducing the surface topography of PC bag surfaces, a reduction in biofilm formation by both bacterial strains was observed after 5 days particularly for $S$. marcescens. The, polar energies of the cells and the surfaces appeared to have little influence on bacterial adhesion as both organisms adhered to the rough surface in greater numbers than the other surfaces, which was the least polar. Therefore, it is suggested that reducing the surface topographies of the PC bags may be an effective strategy to reduce biofilm formation during PC storage. 


\section{Acknowledgements}

This work was undertaken by Manchester Metropolitan University and was funded by the Sir Halley Stewart Trust. The views expressed within this report are those of the authors and not necessarily those of the trust.

\section{Conflict of Interest}

There are no conflicts of interest in this work.

\section{References}

1. Blajchman, M. et al. Bacterial Detection of Platelets: Current Problems and Possible Resolutions, Transfusion Medicine Reviews, 2005, 19(4), 259-272.

2. Greco, C. et al. Staphylococcus epidermidis forms biofilms under simulated platelet storage conditions, Transfusion, 2007, 47, 1143-1153.

3. Greco-Stewart, V. et al. Serratia marcescens strains implicated in adverse transfusion reactions form biofilms in platelet concentrates and demonstrate reduced detection by automated culture, The International Journal of Transfusion Medicine, 2012, 102, 212-220.

4. Martini, R. et al. Bacteriological analysis of platelets and cases of septic reactions associated with transfusion of contaminated samples, Transfusion and Apheresis Science, 2012 47, 313-318.

5. Brecher, E. and Hay, S. Bacterial Contamination of Blood Components, Clinical Microbiology Reviews, 2005, 18(1), 195-204.

6. Corash, L. Bacterial contamination of platelet components: potential solutions to prevent transfusion-related sepsis, Expert Review of Hematology, 2011, 4(5): 509-525. 
7. Kou, Y., Pagotto, F., Hannach, B. and Ramirez-Arcos, S. Fatal false-negative transfusion infection involving a buffy coat platelet pool contaminated with biofilm-positive Staphylococcus epidermidis: a case report, Transfusion Complications, 2015, 55, 2384-2389.

8. Schrezenmeier, H. et al. Bacterial contamination of platelet concentrates: results of a prospective multicenter study comparing pooled whole blood-derived platelets and apheresis platelets, Transfusion, 2007, 47(4), 644-652.

9. Dumont, L. et al. Screening of single-donor apheresis platelets for bacterial contamination: the PASSPORT study results, Blood Components, 2010, 50(3), 589-599.

10. Brecher, M., Holland, P., Pineda, A., Tegtmeier. G., and Yomtovian, R. Growth of bacteria in inoculated platelets: implications for bacteria detection and extension of platelet storage, Blood Components, 2000, 40(11), 1308-1312.

11. Vedy, D. et al. Bacterial contamination of platelet concentrates: pathogen detection and inactivation methods, Hematology Reviews, 2009, 1(5), 22-28.

12. Ramírez-Arcos, S. et al. Fatal septic shock associated with transfusion transmitted Serratia marcescens, Transfusion, 2006, 46(11), 679-81.

13. Donlan, R. Biofilms: Microbial Life on Surfaces, Emerging Infectious Diseases, 2002, 8(9), 881-890.

14. Desrousseaux, C., Sautou, V., Descamps, S., and Traore, O. Modification of the Surfaces of Medical Devices to Prevent Microbial Adhesion and Biofilm Formation, Journal of Hospital Infection, 2003, 85, 87-93. 
15. Busscher, H. and van der Mei, H. How Do Bacteria Know They Are on a Surface and Regulate Their Response to an Adhering State?, PLoS Pathogens, 2012, DOI: 10.1371/journal.ppat.1002440.

16. Bjarnsholt, T. The Role of Bacterial Biofilms in Chronic Infections, ACTA Pathologica, Microbiologica et Immunologica Scandinavica, 2013, 121(Suppl. 136), 1-54.

17. Rutherford, S. and Bassler, B. Bacterial Quorum Sensing: Its Role in Virulence and Possibilities for Its Control, Cold Spring Harbor Perspectives in Medicine, 2012, DOI: 10.1101/cshperspect.a012427.

18. Benjamin, R. and Wagner, S. The residual risk of sepsis: modelling the effect of concentration on bacterial detection in two-bottle culture systems and an estimation of falsenegative culture rates, Transfusion, 2007, 47(8), 1381-1389.

19. Whitehead, K.A., Colligon, J., and Verran, J. Retention of microbial cells in substratum surface features of micrometer and sub-micrometer dimensions, Colloids and Surfaces BBiointerfaces, 2005, 41, 129-138.

20. Verran, J., Packer, A., Kelly, P. and Whitehead, K.A. The Retention of bacteria on hygienic surfaces presenting scratches of microbial dimensions, Letters in Applied Microbiology, 2010, 50, 258-263.

21. Van Oss, C.J., Chaudhury, M.K., and Good, R.J. Interfacial Lifshitz-van der Waals and polar interactions in macroscopic systems, Chemical Reviews, 1988, 88(6), 27-941.

22. Van Oss, C.J., and Giese, R.F. The hydrophilicity and hydrophobicity of clay minerals, Clays and Clay Minerals, 1995, 43(4), 474-477. 
23. Rosenberg, M., Gutnick, D., and Rosenberg, E. Adherence of bacteria to hydrocarbons: a simple method for measuring cell surface hydrophobicity, FEMS Microbiology Letters, 1980, 9(1), 29-33.

24. Handbook of plasticisers ( $3^{\text {rd }}$ Edn.), Ed. Wypych G., Ch. 10.3 Spectral properties, pp. 223-224, ChemTec Publishing, Toronto, 2017.

25. Gönen, M., Öztürk, S., Balköse, D., Okur, S., and Ülkü, S. Preparation and Characterization of Calcium Stearate Powders and Films Prepared by Precipitation and Langmuir-Blodgett Techniques, Industrial and Engineering Chemistry Research, 2010, 49, $1732-1736$.

26. National Institute of Standards and Technology (NIST) Web Book, http://webbook.nist.gov/cgi/cbook.cgi?Scan=cob1069\&Type=IR (accessed 22 ${ }^{\text {nd }}$ April 2017) 27. Balköse, D., Gökçel, H.I., Göktepe, S.E., Synergism of $\mathrm{Ca} / \mathrm{Zn}$ Soaps in Poly(vinylchloride) thermal stability, European Polymer Journal, 2001, 37, 1191-1197.

28. Chae, M.S.., Schraft, H., Hansen, L.T., and Mackereth, R. Effects of physiochemical surface characteristics of Listeria monocytogenes strains on attachment to glass, Food Microbiology, 2006, 23(3), 250-259.

29. Skovager, A. et al. Influence of flow direction and flow rate on the initial adhesion of seven Listeria monocytogenes strains to fine polished stainless steel, International Journal of Food Microbiology, 2012, 157(2), 174-181.

30. Szlavik, J. et al. Initial adhesion of Listeria monocytogenes to solid surfaces under liquid flow. International Journal of Food Microbiology, 2012, 152(3), 181-188. 
31. Bellon-Fontaine, M., Rault, J., and van Oss, C.J. Microbial adhesion to solvents: a novel method to determine the electron-donor/electron-acceptor or Lewis acid-base properties of microbial cells, Colloids and Surfaces B: Biointerfaces, 1996, 7(1-2), 47-53.

32. Whitehead, K.A. and Verran, J. The effect of surface topography on the retention of microorganisms: A review, Food and Bioproducts Processing, 2006, 84, 253-25.

33. Bodecchi, L.M., Cocchi, M., Malagoli, M., Manfredini, M. and Marchetti, A. Application of infrared spectroscopy and multivariate quality-control methods in PVC manufacturing, Analytica Chimica Acta, 2005, 554, 207-217.

34. Benavides R., Edge, M., Allen, N.S., The mode of action of metal stearate stabilisers in poly(vinylchloride): II Influence of preheating on induction times and carbonyl formation, Polymer Degradation and Stability, 1995, 49, 205-201.

35. Lu, Y., and Miller, J.D. Carboxyl Stretching Vibrations of Spontaneously Adsorbed and LB-Transferred Calcium Carboxylates as Determined by FTIR Internal Reflection Spectroscopy, Journal of Colloid and Interface Science, 2002, 256, 41-52.

36. Shafrin, E.G. and Zisman, W.A. Constitutive relations in the wetting of low energy surfaces and the theory of the retraction method of preparing monolayers, Journal of Physical Chemistry, 1960, 64(5), 519-524.

37. Dunlap, C., Biresaw, G. and Jackson, M. Hydrophobic and electrostatic cell surface properties of blastospores of the entomopathogenic fungus Paecilomyces fumosoroseus, Colloids and Surfaces B: Biointerfaces, 2005, 46(4), 261-266.

38. Zeraik, A.E. and Nitschke, M. Biosurfactants as agents to reduce adhesion of pathogenic bacteria to polystyrene surfaces: effect of temperature and hydrophobicity, Current Microbiology, 2010, 61(6), 554-559. 
39. Whitehead, K.A. et al. The effect of surface properties of polycrystalline, single phase metal coatings on bacterial retention, International Journal of Food Microbiology, 2015, 197, 92-97.

40. Katsikogianni, M., Spiliopoulou, I., Dowling, D.P., and Missirlis, Y.F. Adhesion of slime producing Staphylococcus epidermidis strains to PVC and diamond-like carbon/silver/fluorinated coatings, Journal of Materials Science-Materials in Medicine, 2006, 17, 679-689.

41. Eginton, P.J., Gibson, H., Holah, J., Handley, P.S., and Gilbert, P. The Influence of Substratum Properties on the Attachment of Bacterial-Cells, Colloids and Surfaces BBiointerfaces, 1995, 5, 153-159. 
Table. 1. Physicochemistry results of the rough, smooth and flattened surfaces. Gibbs free energy $(\Delta G)$, surface energy $\left(\gamma_{s}\right)$, Lifschitz van der Waals forces $\left(\gamma_{s} L W\right)$, acid base components $\left(\gamma_{s} A B\right)$, acid component $\left(\gamma_{s}+\right)$ and base component $\left(\gamma_{s^{-}}\right)$.

\begin{tabular}{lcccccc}
\hline & $\begin{array}{c}\Delta G \\
\mathrm{~mJ} / \mathrm{m}^{2}\end{array}$ & $\begin{array}{c}\gamma_{s} \\
\mathrm{~mJ} / \mathrm{m}^{2}\end{array}$ & $\begin{array}{c}\gamma_{s} L W \\
\mathrm{~mJ} / \mathrm{m}^{2}\end{array}$ & $\begin{array}{c}\gamma_{s} A B \\
\mathrm{~mJ} / \mathrm{m}^{2}\end{array}$ & $\begin{array}{c}\gamma_{s}+ \\
\mathrm{mJ} / \mathrm{m}^{2}\end{array}$ & $\begin{array}{c}\gamma_{s^{-}} \\
\mathrm{mJ} / \mathrm{m}^{2}\end{array}$ \\
\hline Rough & -52.98 & 52.37 & 48.87 & 3.50 & 0.44 & 7.33 \\
\hline Smooth & -50.15 & 49.61 & 45.65 & 3.96 & 0.54 & 7.54 \\
\hline Flat & -40.21 & 53.30 & 45.16 & 8.14 & 1.79 & 9.67 \\
\hline
\end{tabular}


Table. 2. Tensile strength and elongation measurements for the unmodified and flattened surfaces with standard errors.

\begin{tabular}{|c|c|c|c|c|}
\hline \multirow[b]{2}{*}{$\begin{array}{l}\text { Unmodified } \\
\text { PVC }\end{array}$} & \multicolumn{2}{|c|}{$\begin{array}{l}\text { Tensile Strength } \\
(\mathrm{Mpa})\end{array}$} & \multicolumn{2}{|c|}{$\begin{array}{c}\text { Elongation } \\
(\%)\end{array}$} \\
\hline & 15.679 & \pm 0.257 & 329.76 & \pm 19.373 \\
\hline Flattened PVC & 15.145 & \pm 1.531 & 358.72 & \pm 25.019 \\
\hline
\end{tabular}




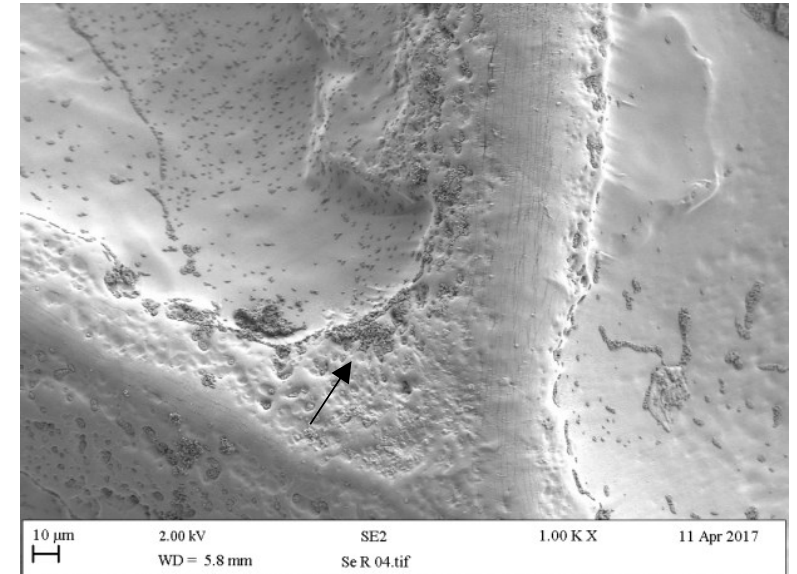

a)

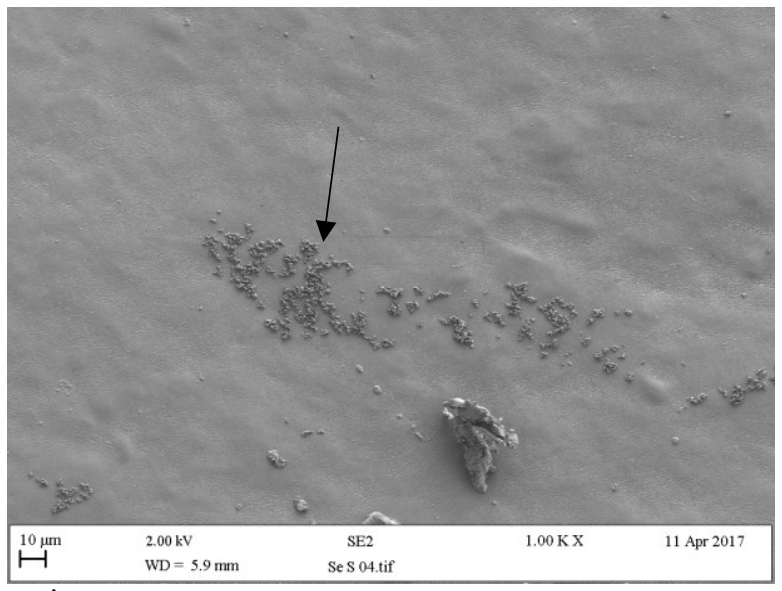

C)

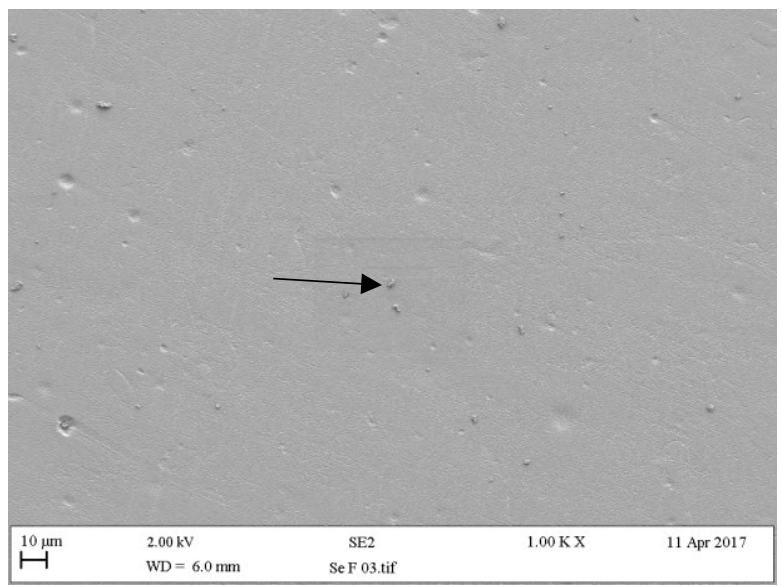

e)

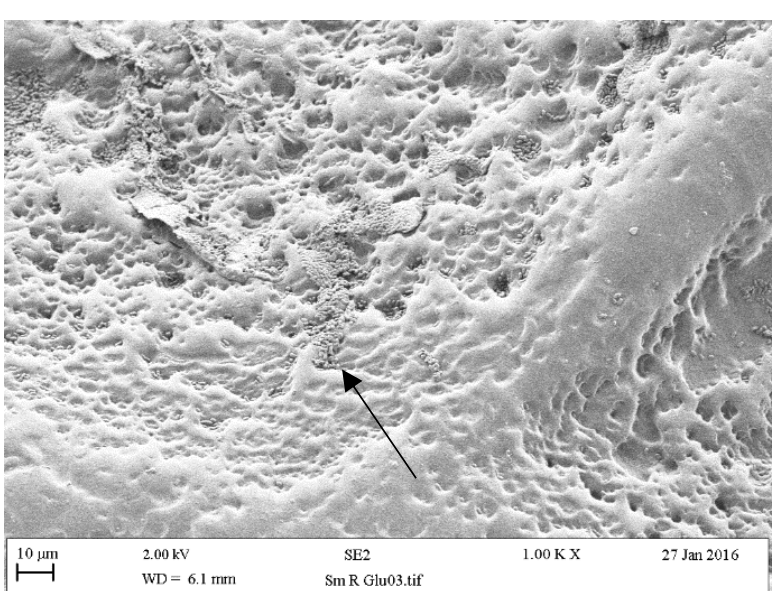

b)
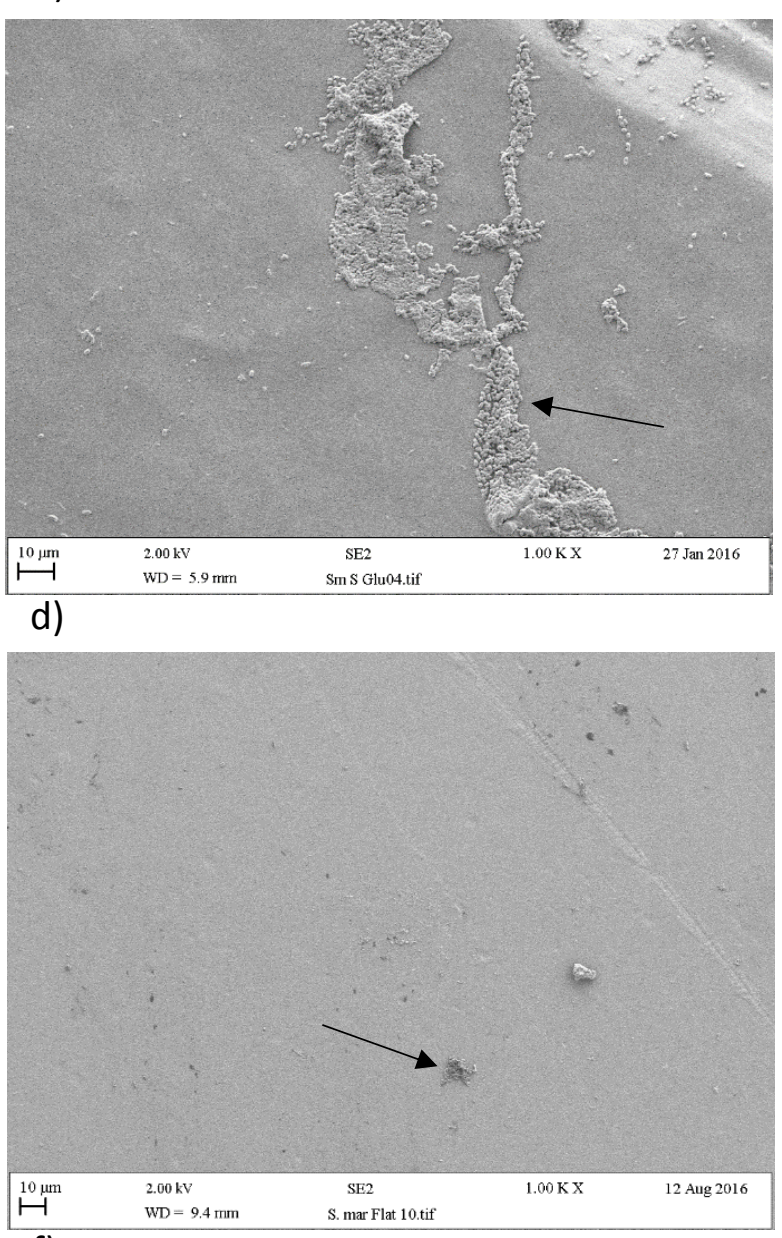

f)

Fig. 1. SEM images of the inoculated p-PVC platelet bags a/b) rough (inside facing), c/d) smooth (inside facing) and e/f) flattened surfaces. Black arrows indicate bacterial cells with a, c and e representing $S$. epidermidis and b, d and f representing $S$. marcescens. 


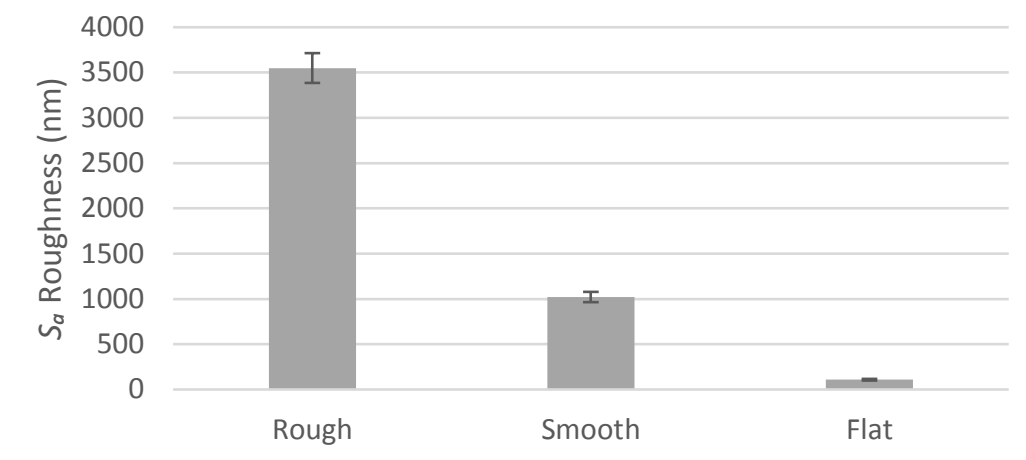

a)

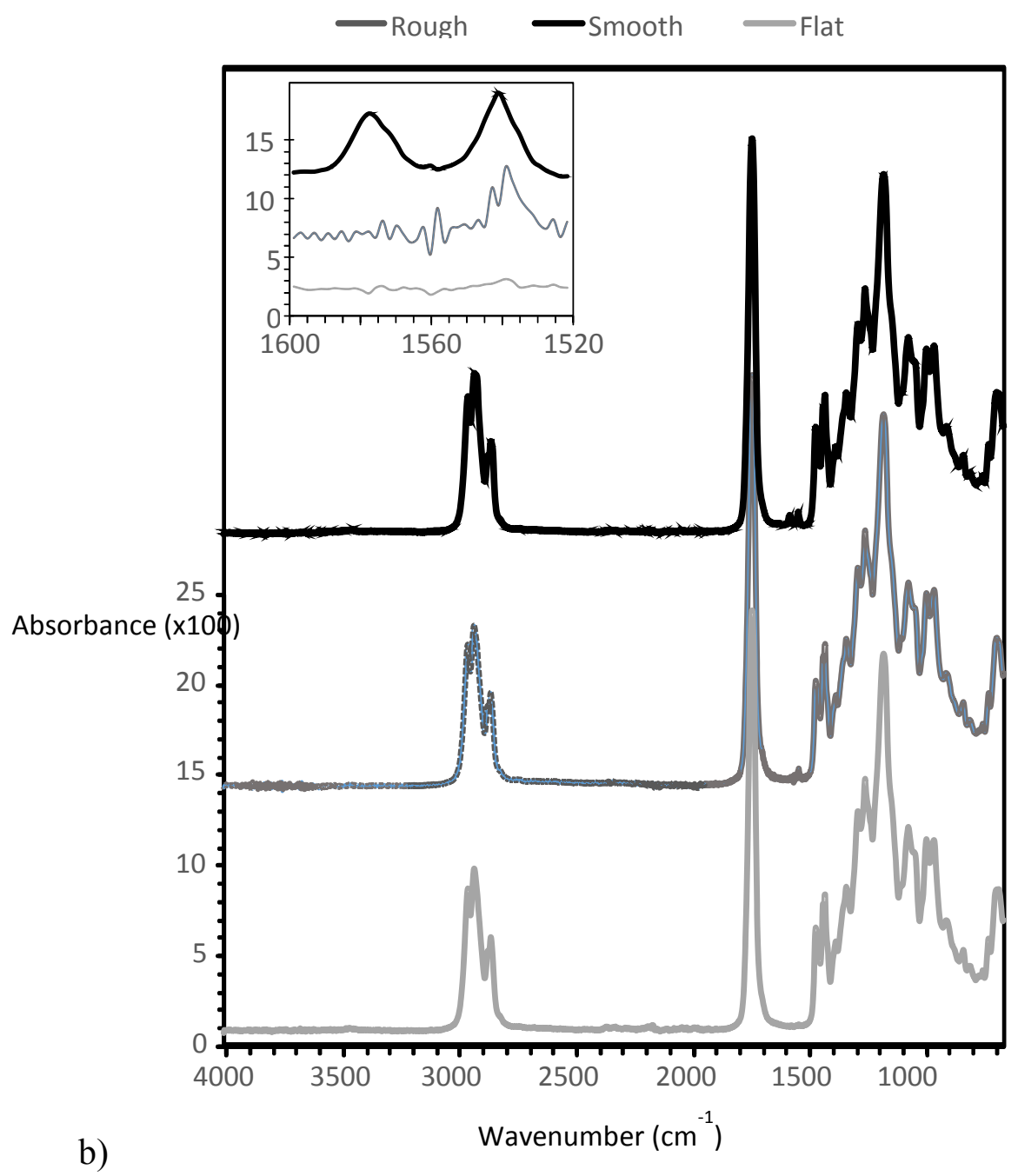

Fig. 2a. Surface roughness ( $S_{a}$ value) of rough, smooth and flat surfaces and b) ATR-FTIR spectra (average of $n=3$ ) of transfusion bag surfaces; unmodified rough side (dark grey), unmodified smooth side (black) and flattened surfaces (light grey). The carboxylate carbonyl antisymmetric stretching vibrations (at 1577 and $1544 \mathrm{~cm}^{-1}$ ) are shown in the inset. 


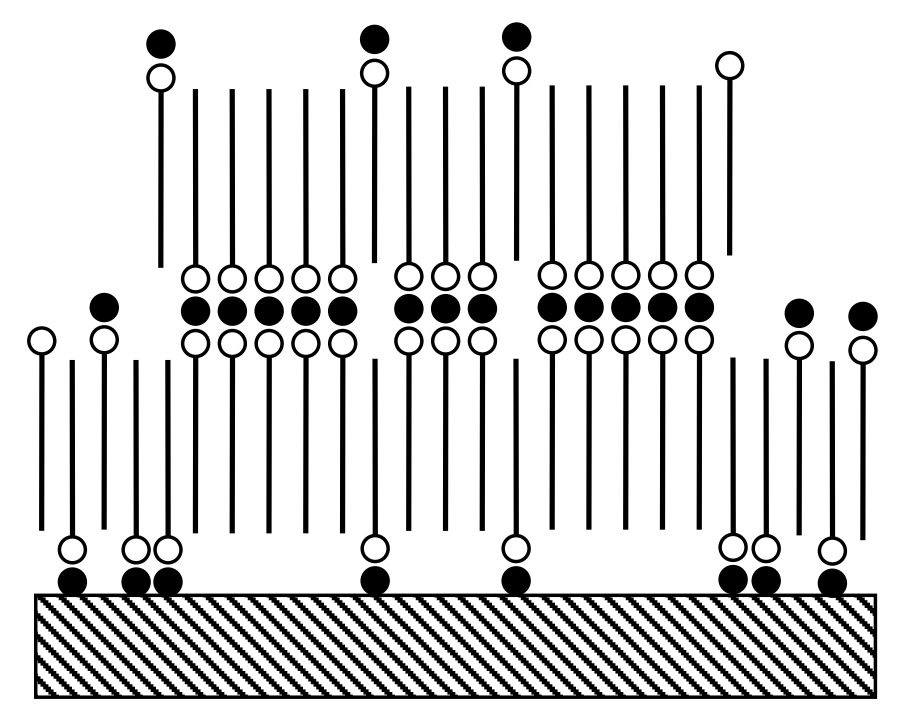

(a)

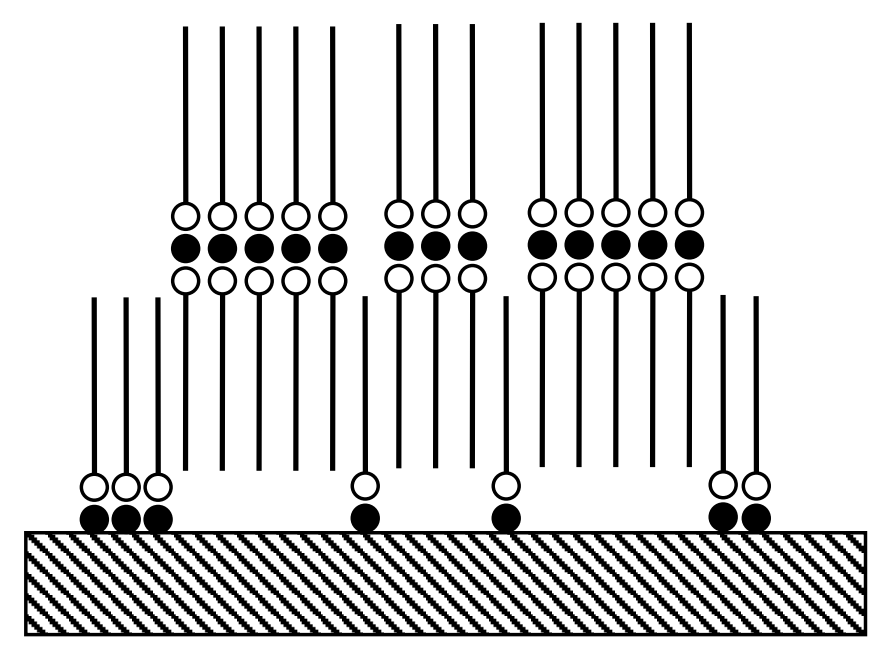

(b)

Fig. 3. Schematic representation of possible adsorbed structure of calcium stearate on the unmodified p-PVC surfaces. a) the presence of calcium/zinc stearates on the surface b) the carboxylate carbonyl absorptions are no longer present. The straight lines represent the $\mathrm{C}_{17} \mathrm{H}_{35}$ chains, the open circles represent the carboxylate group $\left(\mathrm{COO}^{-}\right)$and the closed (black) circles represent the calcium $\left(\mathrm{Ca}^{2+}\right)$ ions (adapted from) ${ }^{35}$ 
a) 100
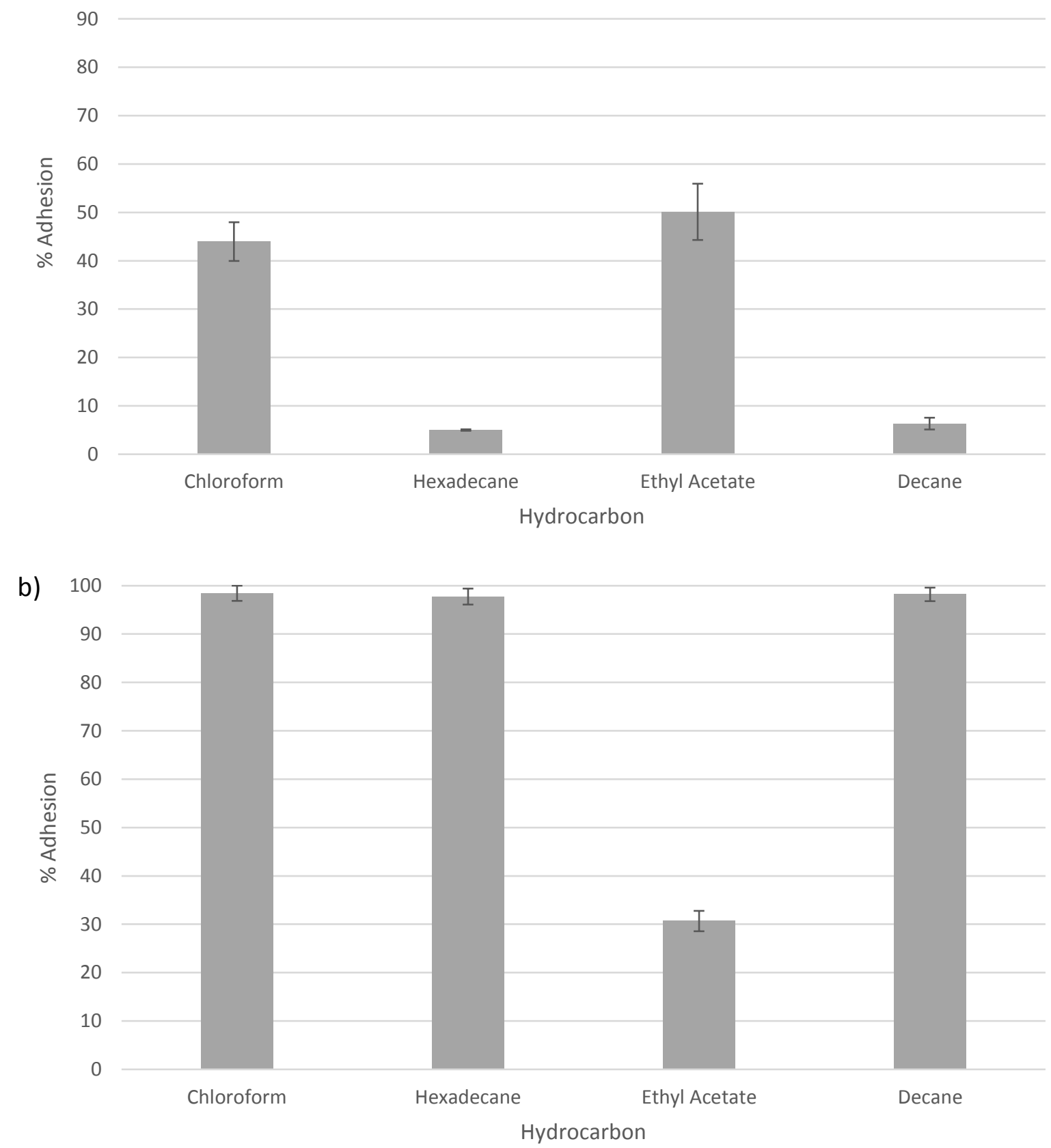

Fig. 4. MATH assays of a) S. marcescens and b) S. epidermidis demonstrating affinity to the apolar n-alkanes decane and hexadecane and to the solvents chloroform (acidic) and ethyl acetate (basic). 
a)

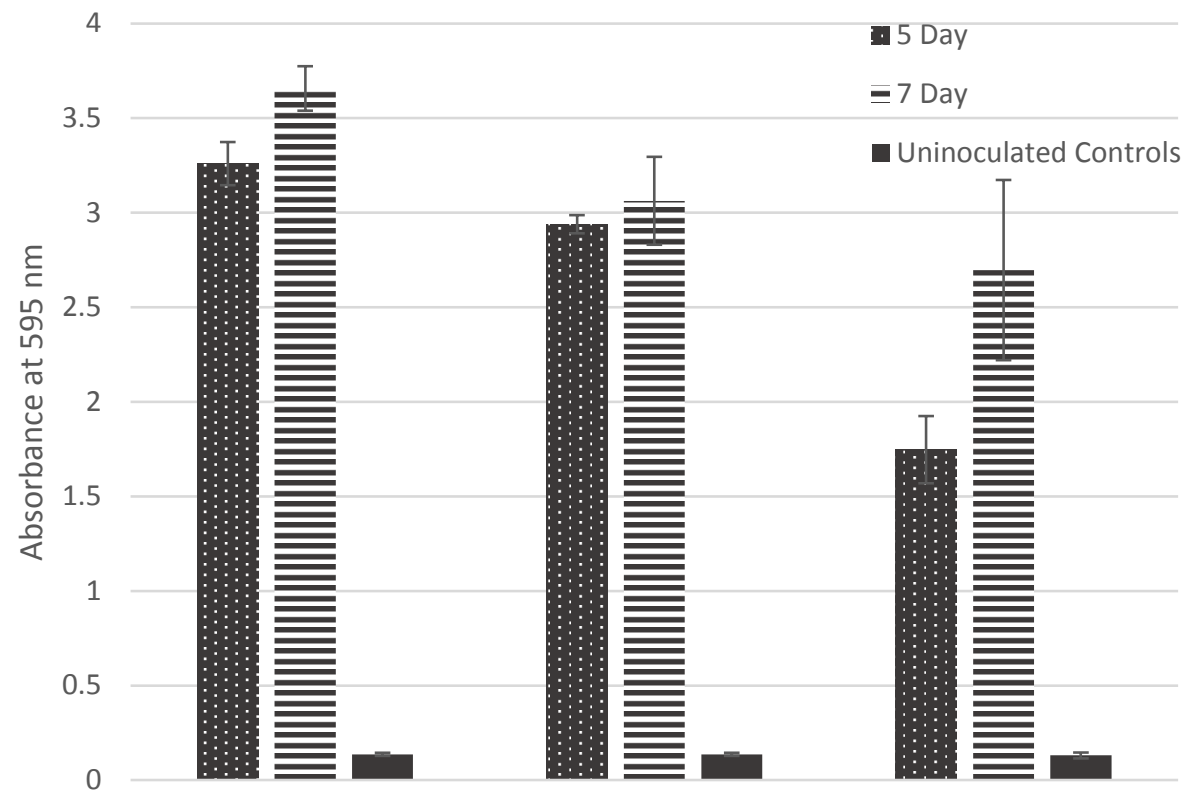

Rough

Smooth

Flat
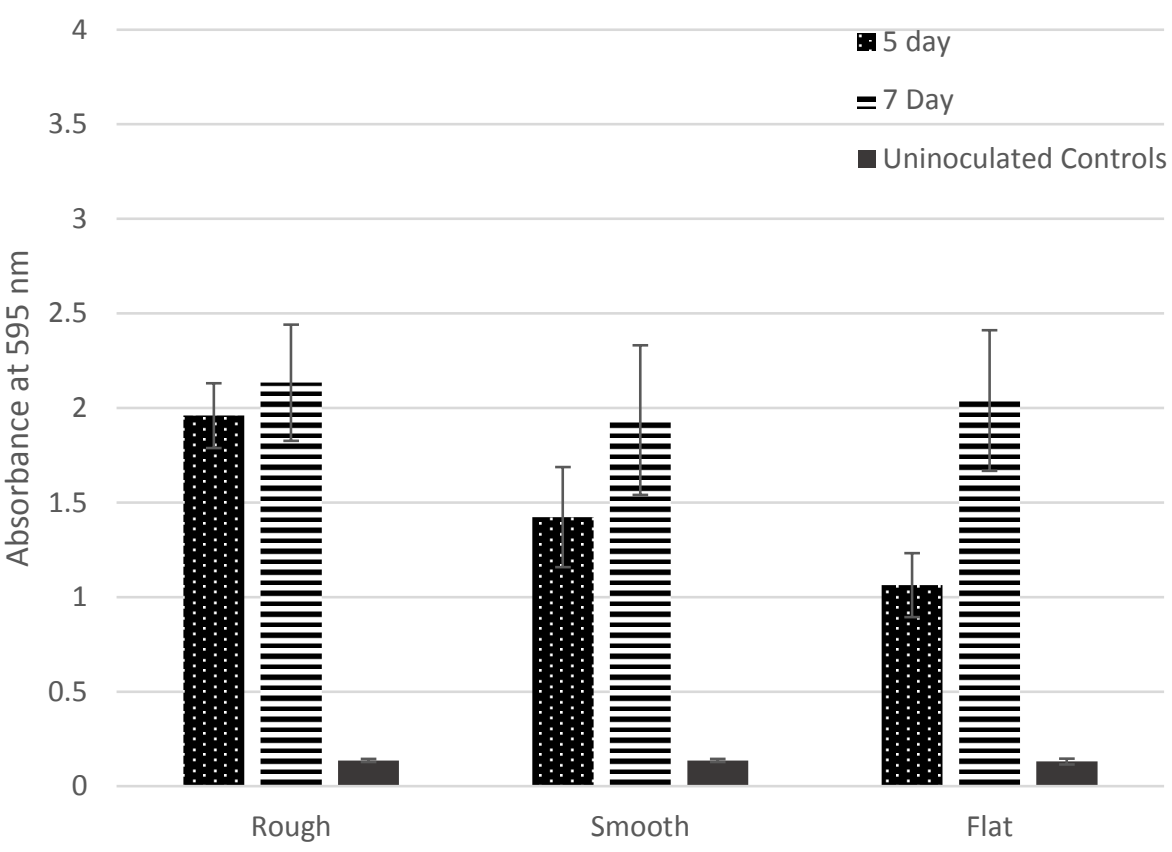

b)

Fig. 5. Five and seven-day biofilm growth of a) $S$. marcescens and b) S. epidermidis on the unmodified (rough and smooth) and flattened p-PVC surfaces. The control surfaces followed the same procedure but were inoculated with sterile distilled water. 